\title{
REVIEW
}

\section{The genetic basis of polycystic ovary syndrome}

N Xita, I Georgiou ${ }^{1}$ and A Tsatsoulis

Division of Endocrinology, Department of Medicine and ${ }^{1}$ Genetics Unit, Department of Obstetrics and Gynaecology, University of Ioannina, Ioannina 45110, Greece

(Correspondence should be addressed to A Tsatsoulis; Email: atsatsou@cc.uoi.gr)

\begin{abstract}
Polycystic ovary syndrome (PCOS) is a common endocrine disorder in women of reproductive age. The disorder is characterized by clinical features of hyperandrogenism, menstrual irregularities and often central obesity and hyperinsulinaemia. PCOS may increase the risk for infertility, type 2 diabetes mellitus, dyslipidaemia, cardiovascular disease and endometrial cancer, emphasizing the need for early diagnosis of the syndrome.

The genetic basis of PCOS is unknown. There is a strong familial component but the mode of inheritance is uncertain and several candidate genes have been proposed to contribute to susceptibility. Not only genes involved in steroid hormone biosynthesis have been studied but also genes associated with the regulation of insulin secretion and action since hyperinsulinaemia is a characteristic of PCOS. So far there is evidence that INS VNTR (insulin variable number of tandem repeats) or CYP11 $\alpha$ (cholesterol side chain cleavage) genes are associated with this syndrome. PCOS appears, however, to be an oligogenic disorder and more studies are necessary to define the genetic basis.
\end{abstract}

European Journal of Endocrinology 147 717-725

\section{Introduction}

Polycystic ovary syndrome (PCOS) is the most common endocrine disorder affecting women of reproductive age. It is considered to be a syndrome not a disease although the term polycystic ovarian disease is often used synonymously, but incorrectly, to describe the syndrome which is manifested by heterogeneous clinical features. The most common features of PCOS are irregular menstrual cycles (oligomenorrhoea or amenorrhoea), signs of androgen excess (hirsutism, acne, alopecia) and often obesity. However, only $5-10 \%$ of women with PCOS express the typical clinical features of the syndrome $(1,2)$. At present the diagnosis of PCOS is usually based on the criteria derived from the 1990 NIH-NICHHD (National Institutes of Health-National Institute of Child Health and Human Development) conference, which are ovulatory dysfunction, clinical evidence of hyperandrogenism and/or hyperandrogenaemia and exclusion of related disorders such as congenital adrenal hyperplasia, hyperprolactinaemia or Cushing's syndrome (3). The finding of polycystic ovaries on ultrasound, which is defined by the presence of eight or more subcapsular follicular cysts $\leq 10 \mathrm{~mm}$ in diameter and increased ovarian stroma, is not a prerequisite for the diagnosis of PCOS according to these criteria (4).
Data on the epidemiology of PCOS are variable, because of the lack of well-accepted criteria for diagnosis. Studies using ultrasonography to identify the presence of polycystic ovaries have reported prevalence rates of $21-22 \%$ among randomly selected women (5). Although menstrual cycle disturbance and hyperandrogenism are more common in women with polycystic ovaries it is generally accepted that many women with polycystic ovaries are endocrinologically normal. Two recent studies have assessed the prevalence of PCOS as defined by both oligomenorrhoea and hyperandrogenism at $4.6 \%$ with a possible range of $3.4-11.2 \%$ (6). Ethnic differences in the prevalence of PCOS have not been well explored. Knochenhauer et al. indicated no significant difference in prevalence between white and black women in the USA, reporting an overall $4.0 \%$ prevalence of PCOS (7). Diamanti-Kandarakis et al. reported a $6.8 \%$ prevalence of PCOS in the Greek island of Lesbos (8) and a similar prevalence $(6.5 \%)$ was found in Caucasian women from Madrid, Spain (9). There are also significant ethnic and racial variations in the clinical presentation of PCOS, the frequency of obesity, insulin resistance and the incidence of diabetes mellitus. A study comparing women with PCOS from the USA, Italy and Japan reported less obesity and hirsutism among Japanese women, yet comparable rates of biochemical androgen excess and insulin resistance (10). Dunaif et al. (11) studied the 
effect of PCOS and ethnicity on insulin action comparing Caribbean-Hispanic women with non-Hispanic Caucasian women and they found that CaribbeanHispanics with PCOS tended to be the most insulin resistant. The effect of ethnicity on the prevalence and presentation of PCOS was also examined in another study comparing European, Maori and Pacific Island women and it was reported that Maori and Pacific Island women with PCOS were more obese, more insulin resistant and more likely to present lipid abnormalities and infertility than European women (12).

Present data strongly support an association between PCOS and several long-term disease risks. Conditions that have been linked to PCOS include type 2 diabetes, hypercholesterolaemia, hypertension, cardiovascular disease, gestational diabetes mellitus, pregnancyinduced hypertension and endometrial cancer, and recently associations between PCOS and breast cancer and ovarian cancer have been reported $(6,13)$. This emphasizes the need for early diagnosis of the syndrome and close follow-up of women with PCOS.

Several reports have stressed that PCOS is a familial disorder and various features of the syndrome may be differentially inherited (14). However, the genetic basis of the syndrome remains controversial. It is difficult to determine the mode of inheritance of this syndrome because its presentation is heterogeneous and there are no universally accepted diagnostic criteria. In addition there is an absence of an equivalent male phenotype and PCOS primarily affects women of reproductive age. However, a recent study of 150 subjects revealed an autosomal dominant mode of inheritance considering premature balding in men as the primary male phenotype $(15,16)$. On the other hand, there are studies of families with high prevalence of PCOS in which the Mendelian autosomal dominant mode of inheritance cannot explain the mode of inheritance of the syndrome (17) while in another study an X-linked model was postulated (18). As a result, the mode of inheritance remains unclear and more than one gene defect seems to participate in the pathogenesis of the syndrome.

PCOS appears to be an oligogenic disorder. Several genes involved in reproduction, genes affecting the secretion or action of insulin and those involved in obesity and energy regulation have been tested as candidate genes. In particular, attention has been focused on genes coding for steroidogenic enzymes in
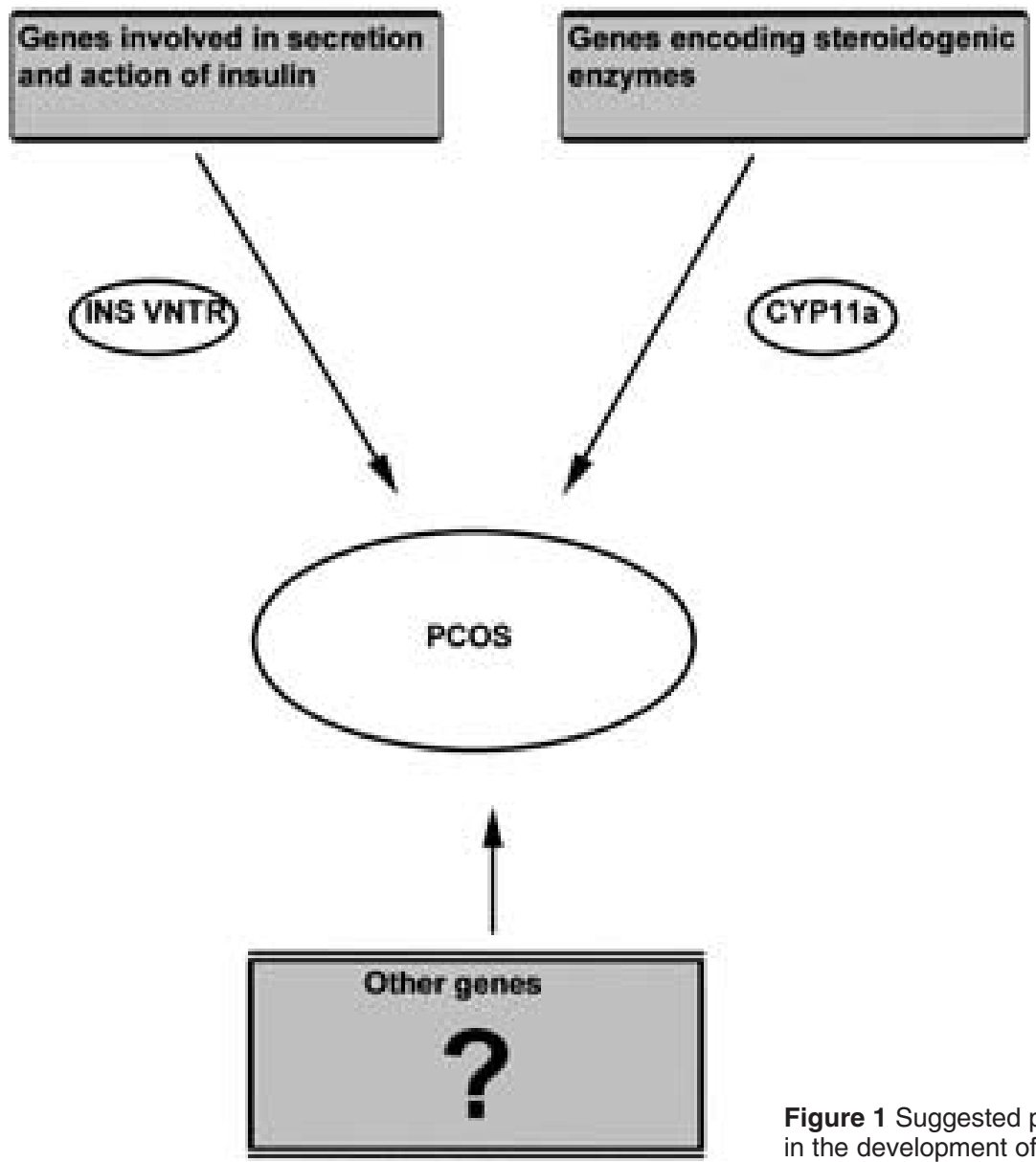

Figure 1 Suggested pathogenic mechanisms in the development of PCOS. 
the androgen biosynthetic pathway and those involved in the secretion and the action of insulin (Fig. 1; Table 1).

The aim of this review is to present a critical analysis of the recent data on the genetics of PCOS.

\section{Genes involved in secretion and action of insulin}

Many studies have revealed abnormalities of both the secretion and action of insulin in women with PCOS. More than a decade ago, convincing evidence showed that most women with PCOS, both obese and lean, have a degree of insulin resistance (resistance to the action of insulin in skeletal muscles and liver) and compensatory hyperinsulinaemia in comparison with normal women of the same age and weight (19). This led to the assumption that genes involved in the secretion and action of insulin may play a role in the pathogenesis of PCOS.

\section{The insulin receptor gene}

The impaired sensitivity to insulin action both in vivo and in vitro led to the hypothesis that genetic abnormalities of the insulin receptor gene or the postreceptor signalling may contribute to the pathogenesis of PCOS.

Table 1 Candidate genes investigated for their possible association with PCOS.

Genes encoding steroidogenic enzymes

Steroidogenic acute regulatory protein (StAR) (48)

CYP11 $\alpha$-cytochrome P450 side-chain cleavage enzyme $(46-49)^{\star}$

CYP17-cytochrome P450 17 $\alpha$-hydroxylase/17,20 lyase $(42,43,48)$

CYP19-cytochrome P450 aromatase $(46,48)$

$17 \beta$-hydroxysteroid dehydrogenase type I, II, III (48)

$3 \beta$-hydroxysteroid dehydrogenase type I, II (48)

Genes involved in secretion and action of insulin

Insulin receptor $(21,22,48)$

Insulin gene VNTR $(34,36-38,48)^{\star}$

Insulin receptor substrate 1 (48)

Insulin-like growth factor-I (48)

Insulin-like growth factor-I receptor (48)

Insulin-like growth factor binding protein $1+3(48)$

Peroxisome proliferator-activated receptor-gamma (48)

Other genes

Androgen receptor $(48,72-75)$

Follistatin $(48,80,81)$

Activin receptor $(48)$

Inhibin A, $\beta-A, \beta-B, C$ (48)

Luteinizing hormone $\beta$-subunit/luteinizing hormone receptor $(48,60-62)$

Follicle-stimulating hormone receptor $(48,82,83)$

Leptin $(48,84)$

Leptin receptor $(48,84)$

*Association with PCOS was found.
The initial assumption was that the resistance to the action of insulin, which is characteristic of PCOS, was due to an abnormality of the insulin receptor. The insulin receptor is a heterotetrameric glycoprotein containing two $\alpha$ - and two $\beta$-subunits. The $\alpha$ - and $\beta$-subunits consist of 1370 amino acids. The insulin receptor gene is composed of 22 exons and it is located on chromosome 19 (20).

Molecular studies of the coding region of the insulin receptor gene in women with PCOS have shown a large number of silent polymorphisms, mainly in intronic regions ( $5^{\prime}$ intron of exon $3,3^{\prime}$ introns of exons 6,7 and 15 and introns of exon 22). These polymorphisms are of little functional significance, although they may alter exon splicing. The majority of these polymorphisms also have been identified in normal subjects and are considered to be common polymorphisms which do not lead to remarkable disturbance of the function of the insulin receptor. As a result we may conclude that the function of the insulin receptor is probably normal in women with $\operatorname{PCOS}(21,22)$.

There is, however, evidence of a stable abnormality in insulin receptor phosphorylation in cells from women with PCOS. Dunaif et al. (23) described increased insulin-dependent serine phosphorylation of the insulin receptor $\beta$-subunit in skin fibroblast cultures from $50 \%$ of the women with PCOS who were studied, compared with fibroblasts from controls. A similar excessive serine phosphorylation was found in skeletal muscle. The serine-phosphorylated insulin receptor had reduced ability to tyrosine phosphorylate an artificial substrate, suggesting that insulin receptor serine phosphorylation may impair signal transduction, accounting for a post-binding defect in insulin action. It has not been determined whether there is a genetic basis for the increased serine phosphorylation. Some recent studies have shown that the factor which is responsible for the increased serine phosphorylation is extrinsic to the insulin receptor. It may be a variant serine kinase or due to an activation of a kinase as a result of an autocrine factor. This is a possible mechanism for insulin resistance in women with PCOS but its genetic basis remains to be determined.

\section{The insulin gene}

The observation that although insulin resistance is largely reversible by weight reduction in obese women with PCOS, an abnormality of first-phase insulin secretion from $\beta$-cells of the pancreas still exists, led

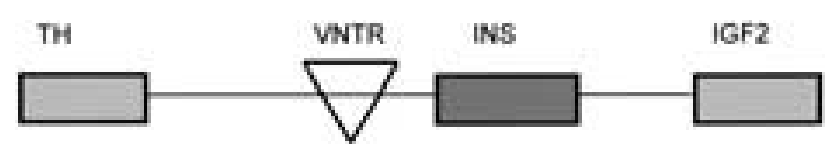

Figure 2 Diagrammatic representation of the TH-INS-IGF2 region on chromosome 11p15.5. TH, tyrosine hydroxylase gene; INS, insulin gene; IGF2, insulin-like growth factor-II gene. 
to investigation of the role of the insulin gene in the pathogenesis of PCOS (24).

The insulin gene has been localized between genes for tyrosine hydroxylase and insulin-like growth factor-II (IGF-II) on 11p15.5 (25) (Fig. 2) The minisatellite of insulin gene INS VNTR (insulin gene variable number of tandem repeats), which lies $5^{\prime}$ to the insulin gene, has been investigated, since this region is directly implicated in the regulation of insulin secretion. This minisatellite is a polymorphic region composed of tandemly repeated 14-15 bp sequences related to the most common repeat ACAGGGGTGTGGGG and positioned $596 \mathrm{bp}$ from the insulin translation starting codon (ATG) in the promoter region. The number of the repeats of the INS VNTR ranges from about 26 to 200 (26). There are three related to the size classes of INS VNTR alleles. Class I are the shorter polymorphic regions and are composed of alleles with 26-63 repeat units (average 40 repeats). Class II alleles are rare in Caucasians and have an average length of about 80 repeat units. Class III are the longest alleles having 141-209 repeat units (average 157 repeats) (26).

The INS VNTR is a functional polymorphism, so it regulates the transcription of the insulin gene and probably the expression of the IGF-II gene which is adjacent to the insulin gene (27). It does not encode any known gene product and it has been shown that an insulin promoter containing the long INS VNTR allele has greater transcriptional activity than one containing a short INS VNTR allele (28). The INS VNTR might transduce transcriptional signals by binding to one or more transcriptional factors, as is usually the case with transcriptional control regions. Kennedy et al. (28) have shown that the INS VNTR contains high-affinity binding sites for the transcriptional factor Pur-1, which has the capacity after binding to INS VNTR to raise basal transcription from the insulin promoter even in cells that do not normally express that gene.

The INS VNTR and especially class III alleles and III/III genotypes have been associated with insulin resistance (29) and diabetic hypertriglyceridaemia (30). Class III alleles have also been associated with central obesity (29) and increased birth weight (31). A meta-analysis supports an association of INS VNTR III/III with type 2 diabetes. Furthermore the type 1 diabetes locus IDDM2 has been mapped to INS VNTR and class I allele homozygosity is associated with an elevated risk of developing type 1 diabetes $(32,33)$.

Waterworth et al. (34) reported an association between PCOS and allelic variation at the INS VNTR locus in three different populations. They showed that class III alleles and especially III/III genotypes are associated with PCOS and are most strongly associated with anovulatory PCOS. The group of women with one or two class III alleles had significantly higher fasting insulin levels and higher mean body mass index than women with I/I genotype. This is in agreement with the observation that hyperinsulinaemia is a more prominent feature in women with polycystic ovaries who have anovulatory menses than in equally hyperandrogenaemic subjects with regular menses (35). It has also been observed that the homozygous genotype III/III is more frequent among women with polycystic ovaries and symptoms than among women with polycystic ovaries without symptoms (34). Waterworth

\section{Cholesterol}

450 sec

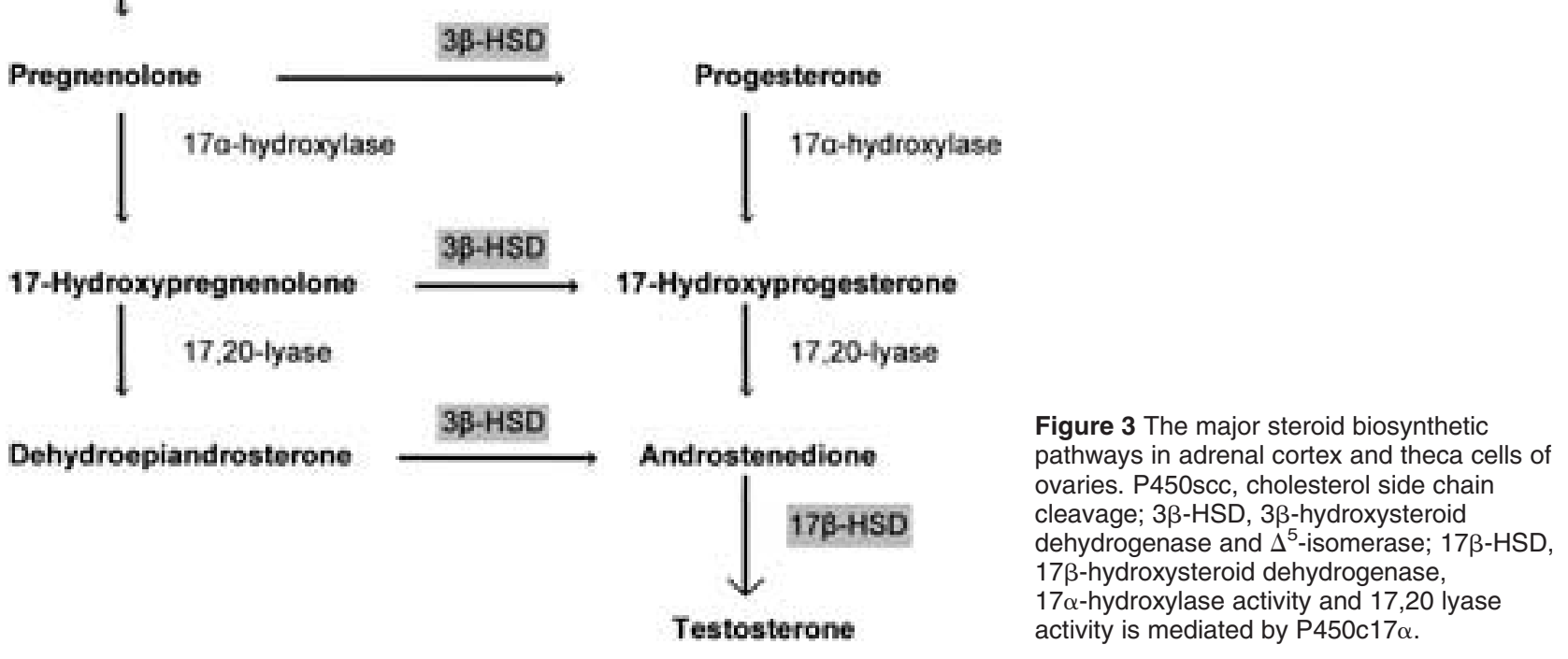


and colleagues (36) also reported that class III alleles are transmitted more often than class I alleles from I/III heterozygous parents to girls with anovulatory PCOS. The transmission of class III alleles from mothers is found to be $47 \%$ while the transmission from fathers is more common. These findings were confirmed in other studies $(37,38)$. If we take into consideration that INS VNTR class III alleles have also been associated with type 2 diabetes (33) we can conclude that the INS VNTR genotype might not only determine the predisposition to anovulatory PCOS but also the concomitant risk for development of type 2 diabetes. This assumption remains to be confirmed, however.

\section{Genes encoding steroidogenic enzymes}

\section{The 17-hydroxylase/17,20-lyase gene (CYP17)}

Recent studies have shown that PCOS may be the result of overfunction of the enzyme which catalyses androgen production (cytochrome P450c17 $\alpha$ ). Cytochrome $\mathrm{P} 450 \mathrm{c} 17 \alpha$ is an enzyme with two functions since it has both $17 \alpha$-hydroxylase and 17,20-lyase activities. In the thecal cells $\mathrm{P} 450 \mathrm{c} 17 \alpha$ converts progesterone to $17 \alpha$-hydroxyprogesterone through its $17 \alpha$-hydroxylase activity and then it converts $17 \alpha$-hydroxyprogesterone to androstenedione through its 17,20-lyase activity (39) (Fig. 3).

Clinical studies have shown an abnormality in the regulation of $17 \alpha$-hydroxylase/17,20-lyase (the ratelimiting step in androgen biosynthesis in the ovaries and the adrenals) in women presenting with PCOS, as evidenced by increased $17 \alpha$-hydroxylase and to a lesser extent 17,20-lyase activity since in these women there is an exaggerated serum $17 \alpha$-hydroxyprogesterone response to stimulation by gonadotrophin-releasing hormone agonists (40). Since the relative ratio of $17 \alpha$-hydroxylase to 17,20 -lyase activity of $\mathrm{P} 450 \mathrm{c} 17 \alpha$ represents a key control locus for androgen biosynthesis, a shift in this ratio could account for aberrations in ovarian and adrenal androgen production. As a result the initial investigations focused on the possible role of CYP17, the gene that codes cytochrome P450c17 $\alpha$ and which is located on chromosome 10q24.3 (41).

A polymorphism has been found in the regulatory region of CYP17 gene. This was a single base change, a $\mathrm{T}$ to $\mathrm{C}$ substitution $34 \mathrm{bp}$ from the translation initiation point in the promoter region. It has been proposed that this change may up-regulate the expression of CYP17 resulting in an increased synthesis of androgens. Initial investigations associated this polymorphism with PCOS but included only a small number of subjects (42). An extension of the initial study to a larger case-control study (96 persons) showed no statistically significant difference in the frequency of this polymorphism between patients with
PCOS and the control group and also no association between this polymorphism and the levels of testosterone (43). Therefore this base change identified in the promoter region of the CYP17 gene is a common polymorphism with no obvious role in the aetiology of PCOS or hyperandrogenaemia.

It has recently been shown that serine phosphorylation is also involved in the post-translational regulation of 17,20-lyase activity and therefore androgen secretion. The serine residues that are phosphorylated and the kinase that mediates the phospholylation remain to be identified. However, this observation raises the possibility that there may be a common aetiology for both the insulin resistance and hyperandrogenism in PCOS (44).

\section{The cholesterol side chain cleavage gene (CYP11 $\alpha$ )}

It has been shown that theca cells from polycystic ovaries produce an excess of progesterone, $17 \alpha-$ hydroxyprogesterone and androstenedione in vitro when compared with normal theca cells (45). It was assumed that the defect in steroidogenesis occurs at or above the level of progesterone biosynthesis. The enzyme for cholesterol side chain cleavage (cytochrome P450scc) catalyses the conversion of cholesterol to pregnenolone, which is the initial and rate-limiting step at the start of the steroid hormone biosynthetic pathway (Fig. 3). It has been hypothesized that up-regulation of this enzyme could lead to increased androgen production (41).

This observation led to studies of the cholesterol side chain cleavage gene (CYP11 $\alpha$ ), which encodes cytochrome P450scc. This gene is located on the long arm of chromosome 15 at position $15 q 24$ (41). In the promoter region of CYP11 $\alpha$ a polymorphic region has been identified. This polymorphism is a pentanucleotide repeat $(\mathrm{tttta})_{n},-528 \mathrm{bp} 5^{\prime}$ from the ATG initiation of the translation site. It is postulated that this polymorphism, being a variable-number-tandemrepeat (VNTR), might play an important role in the regulation of CYP11 $\alpha$ expression, possibly by increasing the rate of transcription. Four-, six-, eight- and nine-repeat-units have been found in the normal population, with the allele carrying four-repeat-units being the most common. PCOS appears to be associated with the absence of the four-repeat-units allele. It has been found that this CYP11 $\alpha$ allele is also associated with serum testosterone levels (46). The association of the (tttta $)_{n}$ polymorphism and PCOS has been confirmed by Diamanti-Kandarakis et al. in Greek patients (47). This suggests that CYP11 $\alpha$ may be a major genetic susceptibility locus for PCOS. However, a more recent study failed to confirm the linkage between the CYP11 $\alpha$ polymorphism and PCOS. Results were initially significant for association with PCOS but after correction for multiple testing no association was 
found between any of the alleles of the CYP11 $\alpha$ and the presence of PCOS (48). Another study in Spain found no influence of this polymorphism in any aspect related to hyperandrogenism (49). The difference between these results and the previous ones may be due to ethnic or racial differences between the studied populations.

\section{The aromatase gene (CYP19)}

Aromatase is an enzyme complex (cytochrome P450arom) that catalyses the conversion of the C19 steroids (androgens) to C18 (oestrogens) (50). Some cases of hyperandrogenism have been reported in patients with aromatase deficiency $(51,52)$. Immunohistochemical studies of polycystic ovaries could not detect aromatase in antral follicles of various sizes (53). On the other hand it has been found that granulosa cells from anovulatory polycystic ovaries are hyperresponsive to follicle-stimulating hormone (FSH) in vitro, displaying significantly greater oestradiol production than granulosa cells from normal ovaries, suggesting no functional deficiency of aromatase in polycystic ovaries (54).

These results led to the study of the aromatase gene (CYP19) located on chromosome 15 at position $15 \mathrm{q} 21.1$ (50). Thus far, there is no evidence of any association of alleles of this gene with PCOS (46).

\section{The luteinizing hormone (LH) $\beta$-subunit gene}

Another gene studied is the $L H \beta$-subunit gene, since $40 \%$ of women with PCOS have hypersecretion of LH and this is associated with anovulation possibly through an adverse effect of LH on oocyte maturation (55).

Two molecular variants of LH have been recently identified. One is an immunologically anomalous LH, caused by two point mutations in exon 2 of the $L H$ $\beta$-subunit gene, which are changes of residues Trp (TGG) to Arg (CGG) at position 8 and Ile (ATC) to Thr (ACC) at position 15. These mutations lead to structural changes in the LH molecules $(56,57)$. This first genetic variant is a universally common polymorphism with a prevalence of $18.5 \%$. The highest frequencies found are in northern Europe and the frequency decreases with increasing geographical distance, being lowest in Asia (58). The biological activity of the LH variant in vitro is found to be greater than that of the wild-type LH but the in vivo half-life is shorter than that of normal LH so the bioactivity in vivo remains unclear (59). The presence of the $\mathrm{LH}$ variant was initially found to be associated with higher levels of serum testosterone in healthy women (60). Tapanainen et al. (61) found lower frequency of this variant in obese PCOS patients suggesting that this LH variant somehow protects obese women from developing symptomatic PCOS and its determination may allow the discrimination between individuals with high and low risks for PCOS, especially in obese women. However, a study in the UK found that occurrence of these mutations was not higher in women with PCOS when compared with healthy women (58). Another study in Singaporean Chinese women confirmed this finding (62).

The other LH variant that has been identified was the result of a single missense mutation in exon 3 of the $L H$ $\beta$-subunit gene, which replaced glycine with serine at amino acid 102 and this was present in $4 \%$ of infertile women $(62,63)$. This variant seems to play a role in female infertility but further studies are required to determine the physiological and pathophysiological significance of this LH variant and its precise role in different types of menstrual disorders.

\section{The androgen receptor (AR) gene}

All androgens act through the AR. The AR belongs to a family of nuclear transcription factors. AR is encoded by a gene located on the X chromosome at Xq11-12 $(64,65)$. The AR, like other members of the steroid receptor family, has three functional domains: the transactivation domain, the DNA-binding domain and the ligand-binding domain. The AR gene contains a polymorphic CAG repeat within exon 1 , which encodes a polyglutamine chain in the N-terminal transactivation domain (66). In healthy populations the number of CAG repeats ranges from 11 to 31 , with the most common allele having 20 repeats (67). The length of the polymorphic CAG repeat sequence is inversely correlated to the AR transcriptional activity. The longer the CAG repeat the lower the transcriptional activity of the AR (68).

Clinical studies support the functional importance of the CAG repeat sequence of the AR gene. Pathological elongation of this CAG repeat polymorphism $(>40$ CAG repeats) causes Kennedy's syndrome, an X-linked syndrome of progressive spinal and bulbar muscular atrophy that is associated with variable degrees of androgen insensitivity (69). Relatively few $(<22)$ CAG repeats are associated with a higher risk of prostate cancer (70) and a lower risk of infertility in men (71).

An association between increased hirsutism and decreased CAG repeat length has been demonstrated in a group of Hispanic women with normal testosterone levels (72) and an association between short CAG repeat length and androgenic skin disorders has also been demonstrated in both men and women (73). However, other investigators were unable to demonstrate differences in the number of repeats between hirsute patients and normal controls and support the theory that hirsutism is associated with skewing of the $\mathrm{X}$-chromosome inactivation which leads to the longer 
of the two AR alleles being preferentially methylated to silence, thus allowing the shorter, and more functional, $\mathrm{AR}$ allele to be expressed on the active X-chromosome (74).

Recently the hypothesis that CAG repeat polymorphism of the AR influences the disease process leading to PCOS has been put forward. It has been shown that an association exists between short CAG repeat length and low serum androgens in the subset of anovulatory patients, suggesting that the pathogenic mechanism of polycystic ovaries in these patients could be due to the increased intrinsic androgenic activity associated with short AR alleles (75).

However, further studies need to be conducted to investigate the role of $\mathrm{AR}$ polymorphisms in the pathogenesis of PCOS.

\section{The gene of follistatin}

Recently Urbanek et al. (48) investigated 37 candidate genes involved in reproduction, insulin secretion and action and energy metabolism and found statistically significant evidence with a marker near the follistatin gene, showing a possible association between the gene of follistatin and PCOS. Follistatin is a binding protein of activin and acts by neutralizing the biological activity of activin both in vivo and in vitro (76). Both follistatin and activin are expressed in several tissues including the ovaries, pituitary, adrenal cortex and pancreas (77). Activin enhances the development of ovarian follicles, inhibits androgen production by ovarian thecal cells, and increases pituitary FSH release and pancreatic $\beta$-cell insulin secretion $(77$, 78). An increase in the activity of follistatin has the opposite effect and this has been confirmed in animals with elevated levels of follistatin which developed phenotypes similar to PCOS (79).

However, sequencing of the follistatin gene has failed to detect any variants associated with PCOS $(80,81)$. Seventeen genetic variants of the gene were studied of which 16 were very rare and the only common genetic variant was a substitute of a single base in the last exon, a region that is untranslated. So the contribution of follistatin gene in PCOS, if any, is only modest.

\section{Conclusions}

The genetic aetiology of PCOS remains unknown. A family history of PCOS is relatively common among PCOS patients, suggesting a significant genetic component, although the mode of inheritance has not been firmly established.

Genetic studies face certain difficulties in their performance, for several reasons, but PCOS is considered to be an oligogenic disorder in which the interaction of a number of genetic and environmental factors (notably dietary) seem to determine the typically heterogeneous, clinical and biochemical phenotype. A potential approach to deal with heterogeneity would be the implementation of strict clinical criteria facilitating the grouping of PCOS patients according to (biochemical and/or clinical parameters) differences or similarities of the phenotype, dietary factors and family history.

Several candidate genes have been tested as the underlying genes for PCOS, but evidence that any of these play a role in PCOS has not been convincingly replicated. The INS VNTR and the CYP11 $\alpha$, which encodes $\mathrm{P} 450$ side chain cleavage, appear to be promising candidate genes at least in some populations. More candidates genes, especially those involved in the metabolic and transport pathways of hormones and accompanying molecules, would be appropriate for further investigations. However, further studies are necessary to determine the genetic associations with certain genes. Our knowledge of the human genome is expanding rapidly. Novel polymorphisms have been identified which may allow detailed mapping of the disease locus for PCOS in the future. This will permit family screening, early diagnosis of women with PCOS and definition of those who are at risk of developing complications.

\section{References}

1 Franks S. Polycystic ovary syndrome. New England Journal of Medicine $1995333853-861$.

2 Balen A. Pathogenesis of polycystic ovary syndrome - the enigma unravels? Lancet $1999 \mathbf{3 5 4} 966-967$.

3 Zawadzki JK \& Dunaif A. Diagnostic criteria for polycystic ovary syndrome: towards a rational approach. In Polycystic Ovary Syndrome, pp 377-384. Eds A Dunaif, JR Givens, F Haseltine \& GR Merriam. Boston, MA: Blackwell, 1992.

4 Franks S. Morphology of the polycystic ovary in polycystic ovary syndrome. In Polycystic Ovary Syndrome, pp 19-28. Eds A Dunai, JR Givens, F Haseltine \& GR Merriam. Boston, MA: Blackwell, 1992.

5 Farquhar CM, Birdsall M, Manning P, Mitchell JM \& France JT. The prevalence of polycystic ovaries on ultrasound scanning in a population of randomly selected women. Australian and New Zealand Journal of Obstetrics and Gynaecology 199434 67-72.

6 Solomon CG. The epidemiology of polycystic ovary syndrome. Prevalence and associated disease risk. Endocrinology and Metabolism Clinics of North America 199928 247-265.

7 Knochenhauer ES, Key TJ, Kahsar-Miller M, Waggoner W, Boots LR \& Azziz R. Prevalence of the polycystic ovary syndrome in unselected Black and White women of the Southeastern United States: a prospective study. Journal of Clinical Endocrinology and Metabolism $1998 \mathbf{8 3} 3078-3082$.

8 Diamanti-Kandarakis E, Kouli CR, Bergiele AT, Filandra FA, Tsianateli C, Spina GG et al. A survey of the polycystic ovary syndrome in the Greek island of Lesbos: hormonal and metabolic profile. Journal of Clinical Endocrinology and Metabolism $1999 \mathbf{8 4}$ 4006-4011.

9 Asuncion M, Calvo RM, San Millan JL, Sancho J, Avila S \& Escobar-Morreale HF. A prospective study of the prevalence of the polycystic ovary syndrome in unselected Caucasian women from Spain. Journal of Clinical Endocrinology and Metabolism 200085 2434-2438.

10 Carmina E, Koyama T, Chang L, Stanczyk FZ \& Lobo RA. Does ethnicity influence the prevalence of adrenal hyperandrogenism 
and insulin resistance in polycystic ovary syndrome? American Journal of Obstetrics and Gynecology 1992167 1807-1812.

11 Dunaif A, Sorbara L, Delson R \& Green G. Ethnicity and polycystic ovary syndrome are associated with independent and additive decreases in insulin action in Caribbean-Hispanic women. Diabetes $1993421462-1468$.

12 Williamson K, Gunn A, Johnson N \& Milsom SR. The impact of ethnicity on the presentation of polycystic ovarian syndrome. Australian and New Zealand Journal of Obstetrics and Gynaecology $200141201-206$.

13 Lobo RA \& Carmina E. The importance of diagnosing the polycystic ovary syndrome. Annals of Internal Medicine 2000132 989-993.

14 Franks S, Gharani N, Waterworth D, Batty S, White D, Williamson $\mathrm{R}$ et al. The genetic basis of polycystic ovary syndrome. Human Reproduction 199712 2641-2648.

15 Ferriman D \& Purdie A. The inheritance of PCO and possible relationship to premature balding. Clinical Endocrinology 1979 $11291-300$.

16 Carey AH, Chan KL, Short F, White D, Williamson R \& Franks S. Evidence for a single gene effect causing polycystic ovaries and male pattern baldness. Clinical Endocrinology 199338 653-658.

17 Hague WM, Adams J, Reeders ST, Peto TE \& Jacobs HS. Familial polycystic ovaries; a genetic disease. Clinical Endocrinology 1988 29 593-605.

18 Givens JR. Familial polycystic ovarian disease. Endocrinology and Metabolism Clinics of North America 198817 771-783.

19 Dunaif A, Segal KR, Futterfeit W \& Dobrjansky A. Profound peripheral insulin resistance, independent of obesity in polycystic ovary syndrome. Diabetes 198938 1165-1174.

20 Goldfine ID. The insulin receptor: molecular biology and transmembrane signaling. Endocrine Reviews 19878 235-255.

21 Talbot JA, Bicknell EJ, Ranjhowa M, Krook A, O’Rahilly S \& Clayton RN. Molecular scanning of the insulin receptor gene in women with polycystic ovarian syndrome. Journal of Clinical Endocrinology and Metabolism 199681 1979-1983.

22 Sorbara LR, Tang Z, Cama A, Xia J, Schenker E, Kohanski RA et al. Absence of insulin receptor gene mutations in three women with polycystic ovary syndrome. Metabolism $1994 \mathbf{4 3}$ $1568-1574$.

23 Dunaif A, Xia J \& Book C. Excessive insulin receptor serine phosphorylation in cultured fibroblasts and skeletal muscle: a potential mechanism for insulin resistance in the polycystic ovary syndrome. Journal of Clinical Investigation $1995 \mathbf{9 6}$ $801-810$.

24 Holte J, Bergh T \& Berne C. Restored insulin sensitivity but persistent increased early insulin secretion after weight loss in obese women with polycystic ovary syndrome. Journal of Clinical Endocrinology and Metabolism 199580 2586-2593.

25 Junien C \& Van Heyningen V. Report of the committee on the genetic constitution of chromosome 11. Cytogenetics and Cell Genetics 199055 153-169.

26 Bell GI, Selby MJ \& Rutter WJ. The highly polymorphic region near the human insulin gene is composed of simple tandemly repeating sequences. Nature $198229531-35$.

27 Paquette J, Giannoukakis N, Polychronakos C, Vafiadis P \& Deal C. The INS. $5^{\prime}$ variable number of tandem repeats is associated with IGF-II expression in humans. Journal of Biological Chemistry 1998 $27314158-14164$.

28 Kennedy G, German MS \& Rutter WJ. The minisatellite in the diabetes susceptibility locus IDDM2 regulates insulin transcription. Nature Genetics 19959 293-298.

29 Weaver JU, Kopelman PG \& Hitman GA. Central obesity and hyperinsulinaemia in women are associated with polymorphism in the $5^{\prime}$ flanking region of the human insulin gene. European Journal of Clinical Investigation 199222 265-270.

30 Jowett NI, Williams LG, Hitman GA \& Galton DJ. Diabetic hypertriglyceridaemia and related $5^{\prime}$ flanking polymorphisms of insulin gene. British Medical Journal $1984 \mathbf{2 8 8} 96-99$.

31 Ong KL, Phillips DI, Fall C, Pouton J, Bennett ST, Golding J et al.
The insulin gene VNTR, type 2 diabetes and birth weight. Nature Genetics 199921 262-263.

32 Bennett ST \& Todd JA. Human type 1 diabetes and the insulin gene: principles of mapping polygenes. Annual Review of Genetics $199630343-370$.

33 Ong KK, Phillips DI, Fall C, Poulton J, Bennett ST, Golding J et al. The insulin gene VNTR, type 2 diabetes and birth weight. Nature Genetics $199921262-263$.

34 Waterworth DM, Bennett ST, Gharani N, McCarthy MI, Hague S, Batty $S$ et al. Linkage and association of insulin gene VNTR regulatory polymorphism with polycystic ovary syndrome. Lancet $1997 \mathbf{3 4 9} 986-990$.

35 Robinson S, Kiddy D \& Gelding SV. The relationship of insulin sensitivity to menstrual pattern in women with hyperandrogenism and polycystic ovaries. Clinical Endocrinology 1993 $39351-355$.

36 Bennett ST, Todd JA, Waterworth DM, Franks S \& McGarthy MI. Association of insulin gene VNTR polymorphism with polycystic ovary syndrome. Lancet 1997349 1771-1772.

37 Eaves IA, Bennett ST, Forster P, Ferber KM, Ehrmann D, Wilson AJ et al. Transmission ratio distortion at the INS-IGF2 VNTR. Nature Genetics $199922324-325$.

38 Michelmore K, Ong K, Mason S, Bennett S, Perry L, Vessey M et al. Clinical features in women with polycystic ovaries: relationships to insulin sensitivity, insulin gene VNTR and birth weight. Clinical Endocrinology 2001 55 439-446.

39 Rosenfield RL, Barnes RB, Cara JF \& Lucky AW. Dysregulation of cytochrome $\mathrm{P} 450 \mathrm{c} 17 \alpha$ as the cause of polycystic ovarian syndrome. Fertility and Sterility 199053 785-791.

40 Rosenfield RL, Barnes RB \& Ehrmann DA. Studies of the nature of 17-hydroxyprogesterone hyperresponsiveness to gonadotropin-releasing-hormone agonist challenge in functional ovarian hyperandrogenism. Journal of Clinical Endocrinology and Metabolism 199479 1686-1692.

41 Miller WL. Molecular biology of steroid hormone synthesis. Endocrine Reviews $19889295-318$.

42 Carey AH, Waterworth D, Patel K, White D, Little J, Novelli P et al. Polycystic ovaries and premature male pattern baldness are associated with one allele of the steroid metabolism gene CYP17. Human Molecular Genetics 19943 1873-1876.

43 Gharani N, Waterworth DM, Williamson R \& Franks S. 5' Polymorphism of the CYP17 gene is not associated with serum testosterone levels in women with polycystic ovaries. Journal of Clinical Endocrinology Metabolism $1996 \mathbf{8 1} 4174$.

44 Znang LH, Rodriguez H, Ohno S \& Miller WL. Serine phosphorylation of human P450c17 increases 17,20-lyase activity: implications for adrenarche and polycystic ovary syndrome. PNAS 199592 10619-10623.

45 Gilling-Smith C, Willis DS, Beard RW \& Franks S. Hypersecretion of androstenedione by isolated thecal cells from polycystic ovaries. Journal of Clinical Endocrinology and Metabolism $1994 \mathbf{7 9}$ $1158-1165$.

46 Gharani N, Waterworth DM, Batty S, White D, Gilling-Smith C, Conway GS et al. Association of the steroid synthesis gene CYP11 $\alpha$ with polycystic ovary syndrome and hyperandrogenism. Human Molecular Genetics 19976 397-402.

47 Diamanti-Kandarakis E, Bartzis MI, Bergiele AT, Tsianateli TC \& Kouli CR. Microsatellite polymorphism (tttta $)_{n}$ at -528 base pairs of gene CYP $11 \alpha$ influences hyperandrogenemia in patients with polycystic ovary syndrome. Fertility and Sterility $2000 \mathbf{7 3}$ $735-741$.

48 Urbanek M, Legro RS, Driscoll DA, Azziz R, Ehrmann DA, Norman RJ et al. Thirty-seven candidate genes for polycystic ovary syndrome: strongest evidence for linkage is with follistatin. PNAS $1999968573-8578$.

49 San Millan JL, Sancho J, Calvo RM \& Escobar-Morreale HF. Role of the pentanucleotide (ttta) $)_{n}$ polymorphism in the promoter of the CYP11 $\alpha$ gene in the pathogenesis of hirsutism. Fertility and Sterility $2001 \mathbf{7 5} 797-802$.

50 Nebert DW, Nelson DR, Adesnik M, Coon MJ, Estabrook RW, 
Gonzalez FJ et al. The P450 gene superfamily: recommended nomenclature. DNA $198981-13$.

51 Harada N, Ogawa H, Shozu M \& Yamada K. Genetic studies to characterize the origin of the mutation in placental aromatase deficiency. American Journal of Human Genetics 199252 666-672.

52 Ito Y, Fisher CR, Conte FA, Grumbach MM \& Simpson ER. Molecular basis of aromatase deficiency in an adult female with sexual infantilism and polycystic ovaries. PNAS $1993 \mathbf{9 0}$ $11673-11677$.

53 Takayama K, Tao T \& Hironobu S. Immunohistochemical study of steroidogenesis and proliferation in polycystic ovarian syndrome. Human Reproduction 199611 1387-1392.

54 Mason HD, Willis DS, Beard RW, Winston RML, Margara R \& Franks S. Estradiol production by granulosa cells of normal and polycystic ovaries: relationship to menstrual cycle and concentrations of gonadotropins and sex steroids in follicular fluid. Journal of Clinical Endocrinology and Metabolism $1994 \mathbf{7 9}$ 1355-1360.

55 Balen Ah, Tan SL \& Jacobs HS. Hypersecretion of luteinizing hormone: a significant cause of infertility and miscarriage. British Journal of Obstetrics and Gynaecology $19951001082-1089$.

56 Furui K, Suganuma N, Tsukahara S, Asada Y, Kikkawa F, Tanaka $\mathrm{M}$ et al. Identification of two point mutations in the gene coding luteinizing hormone (LH) $\beta$-subunit, associated with immunologically anomalous LH variants. Journal of Clinical Endocrinology and Metabolism $1994 \mathbf{7 8} 107-113$.

57 Okuda K, Yamada T, Imoto H, Komatsubara H \& Sugimoto O. Antigen alteration of an anomalous human luteinizing hormone caused by two gonadotropin-type amino-acid substitutions. Biochemical and Biophysical Research Communications 1994200 584-590.

58 Nilsson C, Pettersson K, Millar R, Coerver K, Matzuk M \& Huhtaniemi I. Worldwide frequency of a common genetic variant of luteinizing hormone: an international collaborative research. Fertility and Sterility $199767998-1004$.

59 Haavisto A, Pettersson K, Bergendahl M, Virkamaki A \& Huhtaniemi I. Occurrence and biological properties of a common genetic variant of luteinizing hormone. Journal of Clinical Endocrinology and Metabolism $1995 \mathbf{8 0}$ 1257-1263.

60 Rajkhowa M, Talbot JA, Jones PW, Pettersson K. Haavisto AM, Huhtaniemi I et al. Prevalence of an immunological LH $\beta$-subunit variant in a UK population of healthy women and women with polycystic ovary syndrome. Clinical Endocrinology $1995 \mathbf{4 3}$ 297-303.

61 Tapanainen JS, Koivunen R, Fauser BC, Taylor AE, Clayton RN, Rajkowa $\mathrm{M}$ et al. A new contributing factor to polycystic ovary syndrome: the genetic variant of luteinizing hormone. Journal of Clinical Endocrinology and Metabolism 199984 1711-1715.

62 Ramanujam LN, Liao WX, Roy AC, Loganath A, Goh HH \& Ng SC. Association of molecular variants of luteinizing hormone with menstrual disorders. Clinical Endocrinology $199951243-246$.

63 Liao WX, Roy AC, Chan C, Arulkumaran S \& Ratnam SS. A new molecular variant of luteinizing hormone associated with female infertility. Fertility and Sterility 199869 102-106.

64 Lubahn DB, Joseph DR, Sullivan PM, Willard HF, French FS \& Wilson EM. Cloning of human androgen receptor complementary DNA and localization on the X chromosome. Science $1988 \mathbf{2 4 0}$ 327-330.

65 Brown CJ, Goss SJ, Lubahm DB, Joseph DR, Wilson EM, French FS et al. Androgen receptor locus on the human X chromosome: regional localization to Xq11-12 and description of a DNA polymorphism. American Journal of Human Genetics $1989 \mathbf{4 4}$ $264-269$.

66 Carson-Jurica MA, Schrader WT \& O’Malley BW. Steroid receptor family: structure and function. Endocrine Reviews 199011 $201-218$.

67 Edwards A, Hammond HA, Jin L, Caskey T \& Chakraborty R. Genetic variation at five trimeric and tetrameric tandem repeat loci in four human population groups. Genomics $1992 \mathbf{1 2}$ $241-253$.
68 Chamberlain NL, Driver ED \& Miesfeld RL. The length and location of CAG trinucleotide repeats in the androgen receptor N-terminal domain affect transactivation function. Nucleic Acids Research 199422 3181-3186.

69 LaSpada AR, Wilson EM, Lubahn DB, Harding AE \& Fischbeck KH. Androgen receptor gene mutations in X-linked spinal and bulbar muscular atrophy. Nature 1991352 77-79.

70 Giovannucci E, Stamfer MJ, Krithivas K, Brown M, Brufsky A, Talcott J et al. The CAG repeat within the androgen receptor gene and its relationship to prostate cancer. PNAS $1997 \mathbf{9 4}$ 3320-3323.

71 Dowsing AT, Yong EL, McLachlan RI, de Kretser D \& Trounson A. Linkage between male infertility and trinucleotide repeat expansion in the androgen receptor gene. Lancet $1999354640-643$.

72 Legro RS, Shahbahrami B, Lobo RA \& Kovacs BW. Size polymorphisms of the androgen receptor among female Hispanics and correlation with androgenic characteristics. Obstetrics and Gynecology $199483701-706$.

73 Sawaya ME \& Shalita AR. Androgen receptor polymorphisms (CAG repeat lengths) in androgenetic alopecia, hirsutism and acne. Journal of Cutaneous Medicine and Surgery 1998 3 9-15.

74 Vottero A, Stratakis CA, Ghizzoni L, Longui CA, Karl M \& Chrousos GP. Androgen receptor-mediated hypersensitivity to androgens in women with nonhyperandrogenic hirsutism: skewing of X-chromosome inactivation. Journal of Clinical Endocrinology and Metabolism 199984 1091-1095.

75 Misfud A. Ramirez S \& Yong EL. Androgen receptor gene CAG trinucleotide repeats in anovulatory infertility and polycystic ovaries. Journal of Clinical Endocrinology and Metabolism 2000 85 3484-3488.

76 Shimonaka M, Inouye S, Shimasaki S \& Ling N. Follistatin binds to both activin and inhibin through the common beta-subunit. Endocrinology $1991 \mathbf{1 2 8} 3313-3315$.

77 Mather JP, Moore A \& Li RH. Activins, inhibins and follistatins: further thoughts on a growing family of regulators. Proceedings of the Society for Experimental Biology and Medicine 1997215 $209-222$.

78 Shibata H, Kanzaki M, Takeuchi T, Miyazaki J \& Kojima I. Two distinct signaling pathways activated by activin A in glucose responsive pancreatic beta-cells lines. Journal of Molecular Endocrinology $199616249-258$.

79 Guo O, Kuma TR, Woodruff T, Hadsell LA, DeMayo FI \& Matzuk MM. Overexpression of mouse follistatin causes reproductive defects in transgenic mice. Molecular Endocrinology 199812 $96-106$.

80 Urbanek M, Wu X, Vickery KR, Kao LC, Christenson LK, Schneyer A et al. Allelic variants of the follistatin gene in polycystic ovary syndrome. Journal of Clinical Endocrinology and Metabolism 2000 85 4455-4461.

81 Calvo RM, Villuedas G, Sancho J, San Millan JL \& EscobarMorreale HF. Role of the follistatin gene in women with polycystic ovary syndrome. Fertility and Sterility 200175 1020-1023.

82 Takakura K, Takebayashi K, Wang HQ, Kimura F, Kassahara K \& Noda Y. Follicle stimulating hormone receptor gene mutations are rare in Japanese women with premature ovarian failure and polycystic ovary syndrome. Fertility and Sterility 200175 207-209.

83 Conway GS, Conway E, Walker C, Hoppner W, Gromoll J \& Simoni M. Mutation screening and isoform prevalence of the follicle stimulating hormone receptor gene in women with premature ovarian failure, resistant ovary syndrome and polycystic ovary syndrome. Clinical Endocrinology 199951 97-99.

84 Oksanen L, Tiitinen A, Kaprio J, Koistinen HA, Karonen S \& Kontula K. No evidence for mutations of the leptin or leptin receptor genes in women with polycystic ovary syndrome. Molecular Human Reproduction 2000 6 873-876.

Received 10 April 2002

Accepted 4 June 2002 